\title{
Performance management system implementation in a Southeast European transitional country"
}

\author{
Aleksandar Jankulović, Vladimir Škoric ${ }^{* *}$
}

Very few papers analyse PMS implementation in developing and transitional countries and the importance of PMS implementation for success in transition. Providing a Serbian perspective on PMS implementation, the study aims to identify and analyze important factors and variables that influence PMS implementation in transitional countries and the importance of PMS implementation for success in transition. Obstacles for PMS implementation are connected with a misunderstanding of the need for performance measurement for employees on the lower level, unwillingness for sharing data on the top management level and available resources for PMS implementation.

Sehr wenige Veröffentlichungen analysieren die Verankerung des professionellen Leistungs- Management Systems (PMS) in Entwicklungs- und Schwellenländern und dessen Wichtigkeit für den Erfolg des Transformationsprozesses. Die Studie entwickelt eine serbische Perspektive auf die Verankerung des PMS und identifiziert und analysiert wichtige Faktoren und Variablen, die die Verankerung des PMS in Schwellenländern und deren Bedeutung für den Erfolg des Transformationsprozesses beeinflussen. Widerstände gegen die Verankerung des PMS sind auf der unteren Ebene der Beschäftigten eng verflochten mit dem Unverständnis für die Notwendigkeit einer Leistungsmessung, und auf der obersten Management-Ebene mit dem Widerwillen, eine Teilhabe an Daten und verfügbaren Ressourcen für die Verankerung von PMS zuzulassen.

Keywords: Performance Management System (PMS), Performance measures, Transition, Serbia

\footnotetext{
* Manuscript received: 9.2.12, accepted: 27.9.12 (1 revision)

** Aleksandar Jankulović, Dr., Assistant professor, Belgrade Metropolitan University. Main research interests: Operations management, Performance management system, Quality management systems, Enterprise modelling and integration, Process modelling. Corresponding address: aleksandar.jankulovic@metropolitan. ac.rs

Vladimir Škorić, MSc, PhD student, University Singidunum Belgrade. Teaching associate, Belgrade Metropolitan University. Main research interests: Operations management, Performance management system, Logistic and supply chain management. Corresponding address: vladimir.skoric@metropolitan.ac.rs
} 


\section{Introduction}

Research of Performance Management System (PMS) implementation and its influence in development and transitional countries has largely been overlooked. Hence in an attempt to fill this gap, this study explores PMS implementation from the perspective of a transitional country - country in a transition from state to market economy. The main subject of this paper is PMS characteristics and obstacles for implementation in transitional countries and the impact of performance measures on an organization. In this research we attempted to find the answer on how different contextual factors such as the external environment and market conditions, organizational and ownership structure (including large or small and medium enterprises; private or public organizations; locally and foreign owned), strategy, national and organizational culture influence PMS implementation. In addition, according to our research some other important factors and variables such as knowledge transfer, human capital, company innovativeness, ISO9001 implementation, single or universal concept of PMS, financial or nonfinancial measures and availability of established benchmarking system influence PMS implementation in transitional economies.

In order to present the business environment of analyzed organizations we shall present the Serbian economic and business position. The Serbian transition period started in 2000, the process of transition and restructuring is not finished and the GDP growth is still very slow. From the beginning of the transition period, after political reforms in Eastern European countries, all former communist countries had a degradation of GDP, and some of them with serious dimensions. In 1995 first Poland raised the level from the basic year in 1989, then in 1998 Slovenia did it and in 2000 Hungary raised its GDP level. The only countries that have not managed to raise this level are Serbia and Ukraine. According to EBRD, IMF, wiiw Database and Roland Berger, represent that the Serbian GDP is almost 30\% less than 20 years ago. Figure 1 represents the fact that the raise of the GDP is a consequence of the transition and changes in economy.

The industrial output raising level also represents this trend. The level of industrial production in Serbia in 2009 was on the level of $45 \%$ of the level in 1989 according to reports of the Statistical office of the Republic of Serbia. The coverage of imports by exports in the period $2004-2010$ is on the level of $50 \%$, which represents a low level of export and an uncompetitive economy in Serbia. Participation of private companies in the GDP in Serbia is on the level of $60 \%$. The utilisation rate of the manufacturing industry is around $60 \%$. 
Figure 1: GDP rate 2008 to 1989 in $\%(1989=100 \%)$

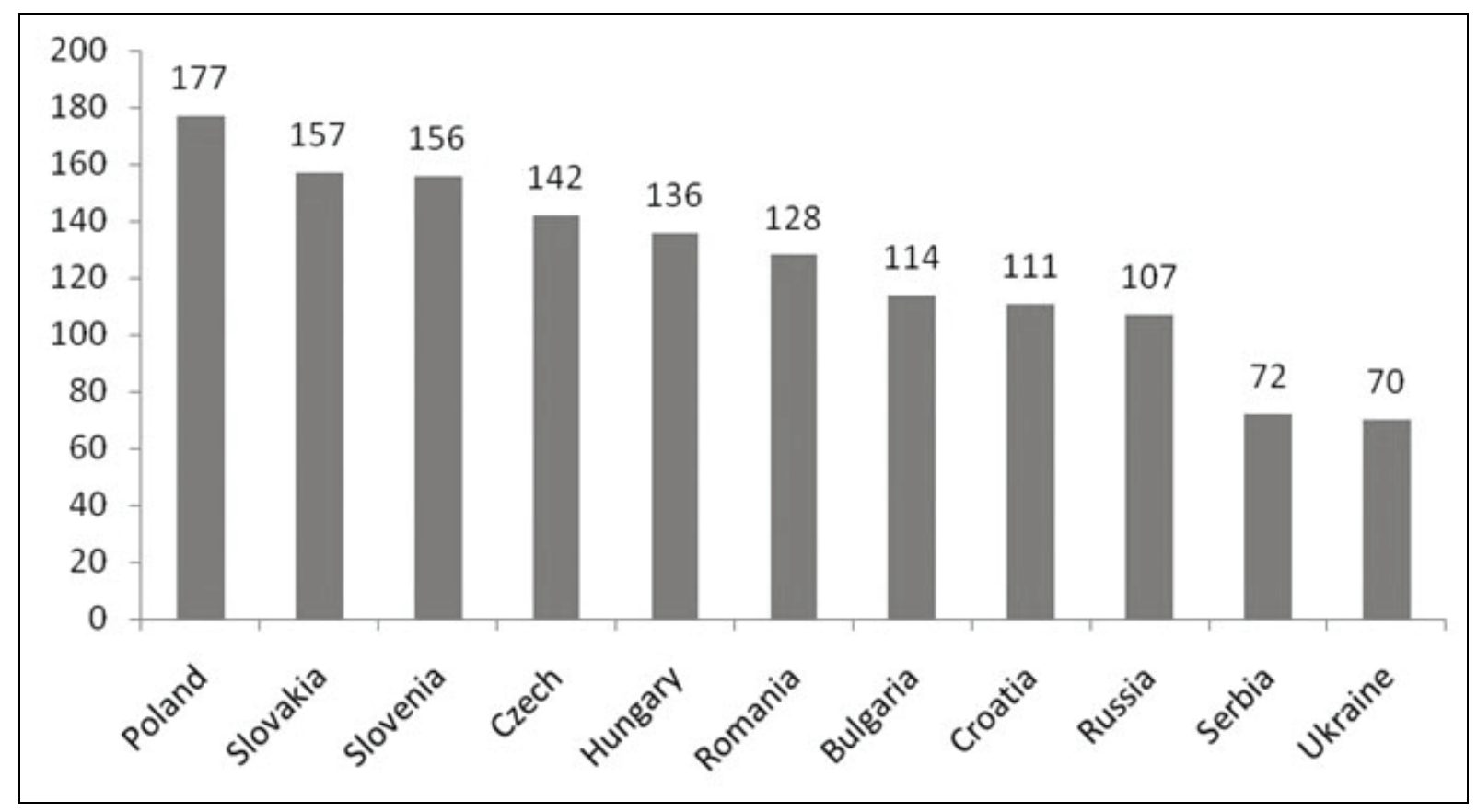

Globalization, deregulation, and economic crisis impose increased efficiency on developing countries. Economic differences demand from these countries a higher level of economic growth in order to reach the level of developed countries since they have to compete on the same global market. Transitional and developing countries considering intensified competition on the open world market with no barriers have to be proactive in offering a higher quality of goods and services, at a lower price level. In order to reach this they need a strategy and to control implementation of this strategy by PMS.

This paper is structured as follows. A review of the literature presents the main contextual factors and variables that have been considered to research PMS implementation in transitional countries such as the importance of performance measurement in developed countries, national and organizational culture, business sector and market conditions, knowledge transfer, human capital, innovativeness of company, ISO9001 implementation, single and universal concept of PMS, financial/nonfinancial measures, large/small and medium enterprises, public/private sector, and availability of established benchmarking system. The research methods section outlines how the research topic emerged and describes the research approach taken. This is followed by a section outlining how different organizations in a transitional country applied PMS with characteristics and obstacles. Finally conclusions are made from literature and research data integrating different variables and the results obtained are discussed. 


\section{Literature review}

Performance management is the process of quantifying action, with measurement as a process of quantification and action leads to performance. It could be defined as the set of metrics used to quantify both the efficiency and effectiveness of actions (Neely 2005). Competitiveness cannot be achieved without managing performance and at the same time developing the skills and competence of employees. Performance management potentially makes the most significant contribution to individual and organizational learning and helps to raise organizational efficiency and promote growth (Adhikari 2010).

According to literature data, PMS implementation and investigation represents an urgent need for developing transitional countries. The development of internal capabilities is strongly influenced by competitive priorities such as cost, quality, flexibility and delivery, which are at the heart of an organization's operations strategy (Boyer/Pagell 2000). In agreement with literature data our findings reveal that for transitional economies organizations that control the obtainment of satisfactory performance (of cost, quality etc.) are of primary importance. Melnyk et al. (2004) emphasized the importance and need for metrics-related research and need to learn how to proactively design and manage them in changing competitive dynamics. On the other hand, Shi (2007) found that organisations have not developed effective metrics to measure process performance. However, Shi (2007) remark is also applicable in our case studies.

Contextual factors such as external environment and market conditions, organizational and ownership structure (including large or small and medium enterprises, private or public organizations, locally and foreign owned), strategy, national and organizational culture are very significant factors influencing PMS implementation. Research of Burn and Stalker (1961), Khandwalla (1972), Waterhouse and Tiessen (1978), emphasized the importance of contextual factors on effective and successful PMS implementation. Therefore we also analyzed among other variables the influence of contextual factors on PMS implementation in a transitional economy.

The dominance of one single PMS concept has been recognised as a potential threat to longer-term professionalization of performance management (Neely 2005). There are a lot of doubts about a universal PMS that can resist a longer period (Kennerley/Neely 2002). Nachum (2010) emphasized differences of performance measures experiences between local and foreign firms analyzed in financial services firms in London. Accordingly, many frameworks have been developed in the past and a consensus about a universal model still has not been reached (Moxham 2009). The fact that there is no universal approach to performance measures could be seen from a variety of research papers (Kennerley/Neely 2002; Neely/Austin 2002; Kuwaiti 2004; Najmi et al. 2005; de Brujin/van Helden 2006; Gerolamo et al. 2008; Gleich et al. 2009; 
Forza/Salvador 2009; Moxham 2009; Lima et al. 2011). Engle et al. (2008), presented the importance of global standardization and local customization in global performance management. Therefore diversity of various approaches and experiences of PMS systems within different cultural and economic heritages is one of the valuable factors. Only very few papers such as Šević Ž. (2005), Hailesilasie G. (2009) and Amizawati et al. (2010), present PMS implementation in developing countries that could be used as a body of knowledge for PMS implementation from a developing country's perspective. Therefore in accordance with previous research our work tried to investigate PMS implementation in developing countries and to contribute to presentation of a local level of PMS implementation with approaches and solutions that have been implemented.

A lot of studies reveal the national cultural influence on PMS. The study of Chang and Birtch (2010) found culture's consequences on the major purposes and practices of performance appraisal in the banking sector from seven countries. The study of Kull and Wacker (2010) finds that specific cultural dimensions are statistically related to quality management effectiveness and performance. Naor et al. (2010) on the other hand suggested that organizational culture has a greater effect on manufacturing performance than national culture or the fit between them. Specificity and organizational culture as well as a sense of belonging significantly influence performance of firms and organizational identity affects the competitive dynamics of firms (Scott/Rhondak 2010). Research papers refer that national and organizational culture influence on PMS is equally important.

Knowledge transfer is another significant factor for PMS implementation. Results of Fugate et al. (2009) in their research indicate the importance of knowledge management processes to operational and overall organizational performance. Malik and Cotabe (2009) showed that organizational learning had significant impact on the performance of emerging market firms. Figuiredo (2011) in his research explores variability across a set of subsidiaries in a local context. It was found that subsidiaries that were able to develop knowledgeintensive linkages with specific internal and external counterparts simultaneously and based on continually increased frequency and improved quality achieved higher innovative performance levels than subsidiaries that developed such linkages with limited frequency and unchanged quality over time. Innovative companies have a strong culture, clear sense of mission and purpose, a well thought out strategy and a business philosophy of continuous improvement, driven by Total Quality Management (TQM) which is successfully realised by PMS (Neely et al. 2001). Nair (2006), in his research, formalizes performance implications of adapting quality management (QM) practice and hypothesized relationship between QM practices and performance. Kaynak (2003) identifies the relationships among TQM practices and examines 
the direct and indirect effects of these practices on various performance levels. According to our research of case studies TQM and implementation of ISO9001 standards have encouraged many organisations to develop and implement performance management, since some of the basic principles of TQM are strongly related to the use of measures. The problem is that ISO9001 implementations in developing countries are at the beginning and a small number of companies are certified.

Research that discovers the financial and nonfinancial nature of measures is also relevant for PMS implementation. The suggestion of Hayes et al. (2005) that the opportunities for creating value in organisations are shifting from managing and measuring tangible assets to managing and measuring knowledge based strategies that develop an organisation's intangible assets is of great importance. Traditionally, organisations analyze performance as a „snapshot in time", or by collecting the same performance information at selected time intervals, hence developing a system for tracking change and underlying trends in performance over time (Fine/Snyder 1999). Performance measures that are focused on financial metrics are used for a long period of time to provide operational control and external financial reporting in private sector organisations (Kuwaiti 2004). New market development and globalisation force companies, specially in developing countries, need to consider their performance in terms of quality of service, flexibility, customization, innovation and rapid response (Neely 2005). Findings of Thaker (2011) prove evidence of the evolution of Business Performance Management to overcome the inadequacies of reliance on accounting based performance measurement to a strategic management system and more recently management learning.

There is also a difference in large and small and medium enterprises (SMEs). Large organisations are more likely to have the time and resources to implement new knowledge and new methods to advance lead performance measurement and benchmarking (Anderson/Mc Adam 2004). Research studies indicate that PMS can play a key role in supporting managerial growth especially in Small and Medium Enterprises (SMEs) (Garengo et al. 2005). However, our findings argue that because of its flexibility and other advantages SMEs are more willing to implement PMS. Since SMEs participate in developing countries with a high percentage, the importance of PMS implementation in these companies is very valuable.

The nature of performance measures is also connected with the ownership of organizations whether they are private or public, locally or foreign owned. Public sector reforms are very important for the development of countries in transition. Performance measurement as a mean of achieving improvements has been a key element of public sector reform. The Norway study performed by Goldeng et al. (2008), found state owned enterprises (SOEs) to play an important role in the regular market. The performance of SOEs is inferior 
compared to privately owned enterprises (POEs) since managers of SOEs have weaker incentives to perform, their principals have less efficient means of monitoring the managers and economic performance is a direct function of the market structure. However, there is a lot of scepticism for the implementation of managerial processes, behaviour, practice and PMS from the private to the public sector (Moxham 2009). Research of Ghobadian et al. (2007) argued that private sector management practices may not result in the transformation of public services and suggest developing a new approach for public specific purposes. They saw different cultural values and expectations of each sector as an obstacle to improve the public service at lower public cost. Firth et al. (2006), investigating companies, refuted researchers who argued that political and regulatory environments have a significant impact on corporate governance systems. Fellows et al. (2010) found that internal resources and competences are most important in organizational performance. Wahin and Bateman (2009) found that some PMS elements have been adopted in most nations, but that much remains to be done before PMS can truly contribute to customer driven and managerial perspectives. In the public sector in Serbia it is very hard to implement PMS which heavily depends on the politico-administrative structure and willingness of politicians (Šević 2005). The mayor problem as reported in this research was to overcome the dominant perceptions of reporting and control which in transitional countries are tightly connected with the need for legalistic compliance. The research of Šević (2005) is one of the rare investigations of performance measurement implementation in private and public sectors in Serbia. Our research confirmed these results and is in agreement with the findings of San Ong and Heng Teh (2008) related to the Malaysian industry where they argued that locally owned firms were found to be more likely to rely on a more traditional, financially oriented PMS than foreign owned companies.

\section{Methodology}

The chosen research methodology was that of multiple case studies which is suited to the interpretive research approach (Yin 2003). Multiple sources of data are embraced and engaged in a recursive, sense-making process, in which the results and discussion are compared and contrasted as suggested by Yin (2003). Six case organizations, as shown in Table 1, were selected to provide a wide range of data from different companies and perspectives according to factors and variables that are presented in the literature part of the paper, as opposed to a single sector study, which created a richness through their inter and intra variation, as suggested Remenyi et al. (1999). These companies were chosen as private with foreign or domestic capital, and public organizations from different business sectors and external environment. Case studies with foreign capital were chosen in order to investigate knowledge transfer and the influence of foreign ownership on the question of PMS implementation. Cases were chosen within different sectors (production, service, sale and distribution, construction, 
health care, city administration), ownership, and size in order to analyze PMS implementation in different surroundings. These cases were integrated through contextual factors and variables important for PMS analyses presented in literature and they are illustrative examples of their sectors in Serbia. Based on the collected data and variables from literature, we analysed case studies and made conclusions.

Semi-structured interviews were held with the managers most familiar with processes, or responsible for each of the leading dimensions under consideration in each of the cases. We developed the protocol for interviews according to specific organization and data that we plan to collect according to literature research presented in this paper. In total 22 managers were interviewed involving a total of six managers in case A, four in case B and three in each of the remaining cases. The managers interviewed for each case was the managing director (or equivalent) and the managers responsible for the key departments. Each of the managers was interviewed at least three times by the interviewer. The repeated interviews were supplemented with specific enquiries involving telephone calls, emails and document exchanges and enabled a relationship of trust and mutual exchange to be established (Remenyi et al. 1999). Key questions and issues were raised in order to reveal the level of PMS implementation, obstacles in implementation, existence of benchmarking and various issues concerning factors and variables important for PMS implementation. The managers were allowed to freely give explanations of their opinions and attitudes. By mixing direct quotations into the integration of data and analysis, the practitioners are allowed to "speak" (Simon et al. 1996) and the full meaning and richness of the opinions and attitudes were allowed to come across. Other data sources included a range of organizational documents.

\section{Results}

Six case organizations from our research are representative of their business sectors, embedded in Serbian realities.

Case A, local government, public organization, was analyzed as one of the most efficient and advanced in Serbia considering their efficiency of citizen services. On the initiative of the mayor, they implemented an example from the USA of a local government system of reporting to citizens on their subjects, problems and all infrastructural and other projects held in their municipality. Knowledge transfer and organizational learning based on the implemented PMS concept in USA existed in this case. The local government is obliged to prepare a budget and a local assembly controls it. Since this municipality is oriented towards better conditions for their citizens, more than $50 \%$ of their budget is oriented towards investment and new projects. Considering this fact and the proactive and management educated mayor of the municipality, they implemented an integrated information system (IS) and enabled implementation of an e- 
government. IS raised the level of municipality efficiency and the level of citizen satisfaction. In this case both financial and nonfinancial measures have been tracked considering the need for overall citizen satisfaction. A great part of this success was connected with developed effective metrics, reports and performance measures integrated in the implemented IS and the possibility to promptly share this data with stakeholders, especially citizens. The situation in the past was totally different in this municipality, and changes were implemented with strong support from the top management. The resistance to change and transformation of the public system is directly connected with the influence of political parties and the fact that municipal authorities are not interested in structural changes, implementation of new technologies and information systems and PMS systems. This example shows that organizational culture, human capital and personnel initiative could raise the level of PMS implementation. This case is embedded tightly in Serbian reality since their management recognized the situation in the domestic environment and understood the need of citizens in domestic circumstances.

Case $B$ account measuring and control system is mostly based on procedures and demands in the national health care system. Implementation of the Occupational and health care system of employees and patients is tracked since it is of great importance for a hospital and as it is a part of government law procedures. The problem is in the non existence of an integrated information system and that performance parameters are stored in excel spreadsheets. One of the most efficient departments, the Department for surgery has implemented some internal procedures for performance measures. They hold a meeting where they analyse daily plans, surgeries and patient status, but without any systematic approach and reports for hospital managers. The influence of organizational culture is in this case presented on the departmental level. Since the hospital is publicly financed, doctors and hospital managers are not interested in patient's opinions and health service levels and therefore nonfinancial parameters are neglected. One of the problems in the health care system is that top hospital managers are doctors, with usually no management education and often with no sense for management and organization. The managerial approach and success is then connected only with personal capabilities. One of the important problems in the public sector is that top managers are appointed according to political party proposals, usually connected with loyalty to party interests and not to quality of management and customer service satisfaction. Accordingly, the management system of a hospital is centralized with a large influence of the Ministry in the field of purchasing, investments, financing and with non existence of an integrated information system and PMS concept. In this case there is no implementation of knowledge transfer and organizational learning based on good world practice and quality management standards. The hospital analysed in our research is one of the typical representatives of the domestic health care system with a very long tradition. 
Case $C$, company for production and construction in public ownership which is in the process of privatization was one of the leading and largest companies in former Yugoslavia in the construction of hydro objects, production and transport of stone materials. A system for controlling exists in the production of materials (quantitative and qualitative) and transport of materials to customers with all elements for cost calculation. The construction part of the company also implements a system for control of project realization. Both performance measurement systems are based on particular needs of departments and therefore they are not based on some predefined PMS concepts. Financial and non financial parameters have been tracked. The Company has an ISO9001 certificate and this is one of the positive influences for performance measurement implementations which prove innovativeness of the company and the need for organizational learning. The organizational culture of this company, as one of the main contractors of projects in Africa and Asia, influences management techniques and principles in PMS implementation. According to interviews with managers, competition with other companies on the market even in the position of public ownership encouraged the company to implement a system for measurement, controlling and improving business. The main obstacles for PMS implementation are in the fact that the company is in transition from public to private ownership and that these processes take too long. This case organization is an adequate representative of domestic transitional organizations from public to private ownership, according to its size, status in domestic and foreign markets and organizational structure.

Case $D$ a privately owned company for distribution, influenced by a foreign partner collects, shares and analyzes data with employees especially salesperson whose salary is directly connected with the sale results. In the beginning of business, performance measurement was only a part of legislation and the need of top management for analysis of sales. These parameters were only financial such as sale information, plans and realization compared to the previous year, results within product groups, total financial results, inventory turnover and cots on a monthly level. The innovative nature of the company has resulted in ISO9001 implementation which improved the performance measurement system and includes collecting non-financial parameters such as customer and employee satisfaction, delivery lead time etc. The collected data, according to the interviewed managers is used for internal comparison which makes a solid competition and opportunity for improvement. Acquired results are used for business decisions and all regional managers can influence such decisions especially if they influence the results on their territory. Data are compared with data from a foreign partner in the company gained in European countries and these results show the specificity of the local Serbian market and trends that are usually different than in developed countries or even in developing countries and the specificity of the organizational culture of the analyzed company. An important aspect of PMS in this company is the need for a large number of 
different data collected from outlets all over the territory of Serbia. Therefore PMS obstacles came from employees since they have a lot of duties and lack of time for something they think is not so useful for collecting and analysing data. A manual system of entering data and preparing graphs and reports for analysis is something that has a negative influence on PMS realization. This case company is a typical representative of a sale and distribution company in Serbian environment with more than 1.000 selling pieces, one distribution centre and outlets all over Serbia.

Case $E_{2}$ a production company, a joint venture with a foreign shareholder, exports $90 \%$ of its final products, of that $65 \%$ to EU countries. The company has an ISO9001 certificate and its products are CE marked. Implementation was a result of strategic plans of innovative management and the need of export conditions to EU countries. According to the company management, stable quality on a high level, adequate prices and a high quality service of product deliveries are the main advantages of the company. Therefore a system of controlling management parameters is of great importance for helping the company improve their business. A system with excel sheets was developed within the company without assistance from the foreign partner in the company and is used together with domestic bookkeeping software. In this case, knowledge transfer from the foreign partner was not realised. Performance measures were based on organizational specificity and the need of management to raise the level of quality and the level of production and sales. PMS was created in house from managers with data included from different PMS implementation practices in other companies. The most important fact in this case was that the management of the company understands performance measures as a need for success and understands their needs considering performance measures. Proof for the quality of the established PMS came from the foreign partner who is one of the largest companies in this field in Europe and also from one of the largest companies from a developed country in Europe who plan to buy this company. One of the main advantages according to them was the quality of products and management system within which they specially recognized the company implemented PMS. The PMS system includes financial and non financial measures. Considering organizational specific PMS, special care is paid to the purchasing process since imported raw materials participate in the final price with $91 \%$. The problem lies in the process of around 3 months from purchasing to delivery time and minimum quantities of order in relation to the price. Collecting data, measuring, analysing and execution of purchasing raw materials is a precondition for market existence and development. The main characteristics of PMS and obstacles were in the period of adapting the bookkeeping system to the need for efficient use of data. This is a typical example of a Serbian production company who try to find their position on foreign markets and therefore have a need for PMS implementation in order to be more successful and competitive. 
Case $F$. The company for the execution of final work in construction, $100 \%$ in domestic private ownership, prepared a PMS for analysing monthly results in total and by projects and project managers. In this case only financial parameters are tracked. A manager in the company explained that the main subject of performance measurement is contracted, invoiced and received payment by the investor - contracting company. In this case as in other construction companies, the main problem is with delays in sending monthly invoices with regard to the actual work done. Because of that, with the follow up of business, a higher degree of attention was paid to the control of invoices and payment by projects. This fact shows the nature of cultural and organizational specificity connected with PMS and its implementation in this case. Obstacles within the system of performance measures prepared in excel datasheets were connected with employees who did not feel the need for tracking data on their projects especially financial. As engineers they believe that their only duty is to realise qualitative work on time and to prepare the invoice and that the payment process and process of collecting and analysing financial data is not a part of their business. The construction industry sector is one of the most important sectors in the Serbian economic status and a large number of companies are dealing like these companies within execution of final work and with not such a large number of workers.

\section{Conclusions}

The lack of resources for PMS implementation, willingness and decisions has become an obvious problem in Serbian organizations. Most enterprises still use their old fashioned reporting templates which consist of several pages of narrative report on financial performance measures with a balance sheet. The information obtained is still not used for management purposes but just to fulfil the legislation. There is also resistance to strategic changes and very slow structural changes in the Serbian public sector which highly influence the domestic market conditions. This fact was also confirmed by Šević (2005). An analyzed company in this paper confirmed that internal capabilities and PMS implementation is strongly influenced by competitive priorities on the market where organization performs business. The case E (Production Company) shows an example that product export on the EU market demands a continuous system of performance measurement of customer satisfaction and business process and product improvement.

According to our research, very important contextual factors in PMS implementation are external environment, the status of market development and competition in one sector. Case studies show that the level of PMS implementation is higher in the case of established competition in the sector and in the case of non interference of the state government. In these circumstances, implementation of PMS and other management techniques could contribute to 
the added value, higher income and higher competitiveness on the world market. We believe this should be the priority of developing countries. In dependence on the competition, environment and human resources, the single concept in each analysed case study was implemented and therefore a universal concept could not be imposed as a final solution.

This paper also presents the situation that individual understanding and effort for PMS implementation is of great importance. Since frames, current situation and economic and social position of a country is not an incentive for PMS, the great importance for raising the level of PMS implementation is in the intellectual (human) capital and the efforts of individuals to spread and explain the values of this methodology and to show on some examples their influence on success. This very influencing factor on PMS implementation directly depends on the availability of quality human resources on the work market and management readiness to attract them. As results from presented case studies showed, one of the main barriers and obstacles in PMS implementation are employees on the lower level and relationships between owner/management and employees. They are not interested in collecting and presenting measures since they observe them as something unnecessary. We have noticed that in analysed organizations the collected data is not shared with employees or even some of them but is used by the top management. Principles of sharing data results in order to achieve better ones are not popular. In one of the analysed organizations, the top management after a long period of thinking and asking their foreign partners agreed to share data with their employees. Our study shows that the owners without a foreign capital partner are convinced that they don't need a system for performance measurement. This is the result of a great level of distrust between the owner and employees that is a characteristic of transitional economies. The studied cases prove that implementation of any kind of tracking performance measures and knowledge shared with employees improved the level of implementation and recognition of PMS. Better results on the market, therefore a higher profit and salaries based on measured performances, improvement and change, raised the willingness of stakeholders to implement PMS.

Individuals that implement knowledge transfer are of great importance and according to our case studies they are one of the prime motivators for successful PMS implementation. Knowledge transfer in the field of implementation technology in our research is based on implementation of Information systems (IS). Depending on the IS implemented, the organization implemented PMS more or less effectively. We also noticed the influence of ERP solutions such as SAP and Microsoft Dynamics and their Business intelligence and Controlling modules on the solutions of IS that are implemented in organizations and therefore the level of implementation efficient PMS.

One of the most important examples of knowledge transfer and an important factor for PMS implementation according to our research is the case with ISO 
9001 implementation in organizations. An important aspect for the implementation of PMS in transition countries is to establish a quality management system ISO9001, since it demands a system of measurement, analysis and improvement. On the other hand, measurement, control and reporting would ensure business data transparency and also improve efficiency and structural changes in a country. These changes could then raise competitiveness of a domestic company and thereby raise the GDP and employment rate. Four organizations from the analyzed cases have an ISO9001 certificate issued by an internationally acknowledged certification company, which made a significant contribution in introducing process approach, defining and measuring business parameters, as well as additional analysis and improvements. In those organizations where ISO9001 has been implemented, the understanding for PMS is on a much higher level. This is evidence that ISO9001 implementation is a good step towards PMS implementation.

Case study analysis indicates the specificity of national and especially organizational culture which is tightly connected with PMS implementation. Although based on a limited number of companies, our findings suggest that every company with its own specialities, development, and ownership, socioeconomic, cultural, organizational, ethical, and other conditions in the business environment needs specific answers for PMS implementation. Our research argues that the culture context factor has a great influence on PMS and that organizational culture highly depends on the owner.

The analysed companies showed different results in understanding the need for PMS implementation considering the status of ownership. Privately owned companies with a foreign partner had exact demands for performance measures, control and improvement. The situation was quite different in public companies where the interest for measuring process performances, results and customer satisfaction is on the basic level of bookkeeping law demands. Only individuals with relevant knowledge and willingness on high positions in public organizations could raise this question and implement some PMS elements. Even if in these organizations they understand the importance of PMS they are not ready to invest in implementation. This result is coherent with the findings of Garengo and Bititci (2007).

Besides ownership, another important contextual factor is organizational structure and the size of organization. SMEs according to our results show lower levels of interest in collecting performance measures and analysis. This is connected in our cases with lack of resources, human capabilities and knowledge to understand, explain and implement PMS in one SME. In a situation when these companies have a higher growth level, they are faced with the need of establishing a serious management system and therefore also a PMS. 
The analysed organizations have no opportunity for benchmarking on the domestic market with regard to some parameters of business excellence. For companies it is very hard to find data about competitive companies and their results and therefore to define and measure important parameters and compete with the competition. It is especially hard to implement comparisons of some non-financial soft parameters. Case studies D and E shows how the possibility of benchmarking with foreign partner companies from all over Europe positively influence the domestic company.

Further research should include PMS analysis in more organizations from Serbia in order to explore in more detail how performance management can be implemented more in transitioning societies like Serbian and to define steps that have to be realized in order to raise the PMS implementation and with it the competitiveness of domestic organizations.

\section{References}

Adhikari, D.R. (2010): Human resource development for performance management: The case of Nepalese organizations, in: International Journal of Productivity and Performance Management, 59, 4, 306-324.

Amizawati, M.A./Nik Nazli, N.M./Muslim, H.S.M (2010): An investigation on PMS attributes in service organizations in Malaysia, in: International Journal of Productivity and Performance Management, 59, 8, 734-756.

Anderson, K./McAdam, R. (2004): A critique of benchmarking and performance measurement: lead or lag?, in: Benchmarking: An International Journal, 11, 5, 465483.

Boyer, K.K./Pagell, M. (2000): Measurement issues in empirical research: improving measures of operations strategy and advanced manufacturing technology, in: Journal of Operations Management, 18, 3, 361-374.

Burns, T./Stalker, G.M. (1961): The management of innovation, in: London: Tavistock publications.

Costa, D.B./Formoso, C.T/Kagioglou, M./Alarcon, L.F. (2004): Performance measurement systems for benchmarking in the construction industry, in: 12th Annual Conference on Lean Construction, August 3-5, Denmark, 1-12.

Chang, F.T./Birtch, T.A. (2010): Appraising performance across borders: An empirical examination of the purposes and practices of performance appraisal in a multi-country context, in: Journal of Management Studies, 47, 7, 1365-1393.

de Brujin, H./van Helden, G.J. (2006): A plea for dialog driven performance -based management systems: evidence from the Dutch public sector, in: Financial Accountability \& Management, 22, 4, 405-423.

Engle, Sr., A.D./Dowling, P.J./Festing, M. (2008): State of origin: research in global performance management, a proposed research domain and emerging implications, in: European Journal of International Management, 2, 2, 153-169. 
Fellows, R, Li, Y./Liu, A. (2010): Organizational performance: A study of China's large construction state-owned enterprises, in: International Journal of Business Performance Management, 12, 2, 136-164.

Forza, C./Salvador, F (2000): Assessing some distinctive dimensions of performance feedback information in high performance plants, in: International Journal of Operations \& Production Management, 20, 3, 359-385.

Figueiredo, P.N. (2011): The role of dual embeddedness in the innovative performance of MNE subsidiaries: Evidence from Brazil, in: Journal of Management Studies, 48, 2, 417-440.

Fine, T./Snyder, L. (1999): What is the difference between performance measurement and benchmarking?, in: Public Management, 81, 1, 24-25.

Firth, M./Fung, P.M./Rui, O.M. (2006): Firm performance, governance structure and top management turnover in a transitional economy, in: Journal of Management Studies, 43, 6, 1289-1330.

Fugate, B.S./Stank, T.P./Mentzer, J.T. (2009): Linking improved knowledge management to operational and organizational performance, in: Journal of Operations Management, $27,3,247-264$.

Garengo, P./Biazzo, S./Simonetti, A./Bernardi, G. (2005): Benchmarking on managerial practices: a tool for SMEs, in: The TQM Magazine, 17, 5, 440-455.

Garengo, P./Biazzo, S./Bititci, U. (2005): Performance measurement systems in SMEs: a review for a research agenda, in: International Journal of Management Review, 7, 1, $25-47$.

Goldeng, E./Grunfeld, L.A./Benito, G.R. (2008): The performance differential between private and state owned enterprises: The roles of ownership, management and market structure, in: Journal of Management Studies, 45, 7, 1244-1273.

Ghobadian, A./Gallear, D./Viney, H./O'Regan, N. (2007): Public sector performance improvement through private sector management practices: a satisfactory solution?, in: International Journal of Business Performance Management, 9, 4, 363-379.

Hailesilasie G. (2009): Determinants of public employees' performance: evidence from Ethiopian public organizations, in: International Journal of Productivity and Performance Management, 58, 3, 238-253.

Kaynak, H. (2003): The relationship between total quality management practices and their effects on firm performance, in: Journal of Operations Management, 21, 4, 405-435.

Kennerley, M./Neely, A. (2002): A framework of the factors affecting the evolution of performance measurement systems, in: International Journal of Operations \& Production Management, 22, 11, 1222-1245.

Khandwalla, P. (1972): The effect of different types of competition in the use of management controls, in: Journal of Accounting Research, 9, 276-295.

Kull, T.J./Wacker, J.G. (2010): Quality management effectiveness in Asia: The influence of culture, in: Journal of Operations Management, 28, 3, 223-239.

Kuwaiti, M.E. (2004): Performance measurement process: definition and ownership, in: International Journal of Operations \& Production Management, 24, 1, 55-78. 
Malik, O.R./Kotabe, M. (2009): Dynamic capabilities, government policies and performance in firms from emerging economies: Evidence from India and Pakistan, in: Journal of Management Studies, 46, 3, 421-450.

Melnyk, S.A./Stewart, D.M./Swink, M. (2004): Metrics and performance measurement in operations management: dealing with the metrics maze, in: Journal of Operations Management, 22, 3, 209-218.

Moxham, C. (2009): Performance measurement. Examining the applicability of the existing body of knowledge to non-profit organisations, in: International Journal of Operations \& Production Management, 29, 7, 740-763.

Nachum, L. (2010): When is foreignness asset or a liability? Explaining the performance differential between foreign and local firm, in: Journal of Management, 36, 3, 714739 .

Najmi, M./Rigas, J./Fan, I.S., (2005): A framework to review performance measurement systems, in: Business Process Management Journal, 11, 2, 109-122.

Nair, A. (2006): Meta-analysis of the relationship between quality management practices and firm performance - implications for quality management theory development, in: Journal of Operations Management, 24, 6, 948-975.

Naor, M./Linderman, K./Schroeder, R. (2010): The globalization of operations in Eastern and Western countries: Unpacking the relationship between national and organizational culture and its impact on manufacturing performance, in: Journal of Operations Management, 28, 3, 194-205.

Neely, A./Filippini, R./Forza, C./Vinelli, A./Hii, Jasper (2001): A framework for analysing business performance, firm innovation and related contextual factors: perceptions of managers and policy makers in two European regions, in: Integrated Manufacturing Systems, 12, 2, 114-124.

Neely, A./Austin, R. (2002): Measuring performance: the operations perspective, in: Neely, A. (Ed.): Business Performance Measurement: Cambridge University Press, Cambridge.

Neely, A. (2005): The evolution of performance measurement research. Developments in the last decade and a research agenda for the next, in: International Journal of Operations \& Production Management, 25, 12, 1264-1277.

Remenyi, D./Williams, B./Money, A./Swartz, E. (1999): Research in Business and Management: Sage, London.

San Ong, T./Heng Teh, B. (2008): Factors influencing the design and use of PMS in the Malaysian electrical and electronics industry, in: International Journal of Economics and Management, 2, 2, 437-457.

Scott, L.R./Rhondak, R. (2010): That's our turf! Identity domains and competitive dynamics, in: Academy of Management Review, 35, 1, 48-66.

Sević, Z. (2005): Measuring performance on a local government level in a transitional country: the case of Serbia, in: International Journal of Public Sector Management, 18, 7, 582-603.

Shi, Y. (2007): Today's solution and tomorrow's problem: the business process outsourcing risk and management puzzle, in: California Management Review, 49, 3, 27-44. 
Simon, A./Sohal, A./Brown, A. (1996): Generative and case study research in quality management, Part 1: theoretical considerations, in: International Journal of Quality \& Reliability Management, 13, 1, 32-42.

Takim, R./Akintoye, A/Kelly, J. (2003): Performance measurement systems in construction, in: Greenwood, D.J. (Ed.), 19th Annual ARCOM Conference, 3-5 September: University of Brighton: Association of Researchers in Construction Management, 1, 423-432.

Thaker, K. (2011): How does business performance measurement perform? An empirical study with reference to leading companies in India, in: International Journal of Business Performance Management, 12, 4, 396-416.

Yin, R. (2003): Case Study Research: Design and Methods, in: Sage, Newbury Park, CA.

Wahin, M.F./Bateman, R., (2009): Public sector human resource management reform across countries: from performance appraisal to performance steering?, in: European J. International Management, 3, 4, 495-511.

Waterhouse, J.H./Tiessen, P.A. (1978): A contingency framework for management accounting systems research, in: Accounting, Organization and Society, 3, 65-76. 